\title{
PLASMA CHOLINESTERASE ACTIVITY IN NEWBORNS AND INFANTS*
}

\author{
ELEMÉr K. Zsigmond, M.D. AND John R. Downs, D.D.s., M.s.†
}

Since SUCCinylcholine (Sch) is the most commonly used muscle relaxant in anaesthetic practice, considerable research has been conducted on its mode of action and metabolism. It is known that Sch is hydrolyzed by plasma cholinesterase (PChE). ${ }^{1}$ Therefore, in the presence of reduced PChE activity, the intensity and the duration of the neuromuscular block is prolonged. ${ }^{2}$ After the discovery of an inherited, atypical PChE variant by Kalow et al. ${ }^{3}$ the cognizance of conditions which may influence PChE activity, such as sex, age, and various disease states, became indispensable for the anaesthesiologist in the assessment of safe doses of Sch., $2,4,5$

Although several reports have called attention to the development of cardiac arrhythmias and/or cardiac arrest caused by the intravenous administration of Sch in infants, especially in combination with halothane anaesthesia ${ }^{6,7}$ a comprehensive review of the literature ${ }^{8}$ on cholinesterases revealed no baseline information on the PChE activity of newborns and infants. Therefore, a systematic investigation of the PChE's of newborns and infants was undertaken.

\section{Materials and Methods}

PChE activity was determined in freshly-obtained, heparinized, blood from the umbilical vein of 22 healthy newborns and from the antecubital vein of 20 healthy, well-nourished and unmedicated infants from birth to the age of six months. All of the newborns were delivered at full term; the one-minute Apgarscore was greater than 7 in every instance. To provide a control series of adults, the PChE activity of 175 male and 147 female, healthy, unmedicated volunteers was also determined.

The PChE activity was determined with Foldes's modification of Kalow's ultraviolet spectrophotometric technique.,3 The substrates used were purified benzoylcholine chloride $(\mathrm{BeCh})$ and procaine hydrochloride (Proc). The final concentrations of both substrates were $5.0 \times 10^{-5} \mathrm{M}$. The final plasma dilutions were 1:200 with BeCh and 1:10 or 1:20 with Proc substrate. All measurements were made at $37 \pm 0.2^{\circ} \mathrm{C}$ and $\mathrm{pH} 7.4$ in a sodium phosphate buffer of $0.025 \mathrm{M}$ $\mathrm{Na}$ concentration. The determinations were run in duplicate.

- Presented at the Annual Meeting of the American Medical Association, Section on Anaesthesiology, Atlantic City, New Jersey. From The Department of Anaesthesiology, Allegheny General Hospital, Pittsburgh, Pa. 15212, U.S.A.

$\nmid$ Dr. Zsigmond is Director of Anaesthesia Research and Education, Allegheny General Hospital, Pittsburgh, Pennsylvania 15212, U.S.A. Present Address: University of Michigan Medical Center, Ann Arbor, Michigan 48104, U.S.A. Dr. Downs is an Oral Surgeon. This work was formerly presented in a thesis for the partial fulfillment of the requirements of MDM at the University of Pittsburgh, School of Dentistry, Pittsburgh, Pennsylvania 15213, U.S.A. Currently in practice of oral surgery in Owosso, Michigan, U.S.A. 
The inhibitors used were commercially prepared and purified dibucaine hydrochloride (Nupercaine hydrochloride), neostigmine bromide (Prostigmine bromide), and succinyldicholine chloride (Anectine, Suxamethonium, Quelicin, Sucostrin). The inhibitory effect was observed with the inhibitor concentrations presented in Tables I and II. Kinetic studies were also carried out with various $\mathrm{BeCh}$ and inhibitor concentrations to determine whether the inhibition was competitive or non-competitive with the three substrates.

\section{Results}

Because of the sex difference in PChE activity reported by Shanor et al., ${ }^{4}$ the results are grouped and analyzed according to sex, as shown in Tables I and II. It is evident that there was no significant difference at the $p<0.05$ levelt between newborns and infants of identical sex with respect to the hydrolysis rates of either BeCh or Proc.

The comparison of the mean hydrolysis rates of BeCh and Proc by the PChE's of infants and newborns with the corresponding means of normal male and female adults indicated that the mean PChE activity of infants and newborns was found to be about 50 per cent of that of adults. The per cent inhibition of $\mathrm{BeCh}$ hydrolysis by dibucaine and $\mathrm{Sch}$ of neonatal and infant PChE was identical with that of adults. In contrast to adults, the PChE of infants and of newborns was relatively resistant to neostigmine inhibition.

Double reciprocal plots of the various concentrations of neostigmine, dibucaine, and Sch versus BeCh hydrolysis rates (Figures 1, 2, and 3) showed a competitive inhibition of the BeCh hydrolysis with all three inhibitors tested. These findings agree with the results of previous investigations, ${ }^{2,3,9}$

\section{Discussion}

On the basis of the findings, it may be concluded that the PChE of healthy, full-term newborns and infants from birth to six months hydrolyze BeCh and Proc at half the rate of that of healthy, unmedicated adults. This observation tends to support the earlier findings of Bleisch and Schwachman ${ }^{10}$ that newborns have a markedly lower PChE activity than adults. The infants studied by these authors, however, had severe organic diseases and therefore no valid conclusion could be drawn on the PChE activity of healthy, normal infants. Our findings further corroborate the results of McCance et al. ${ }^{11}$ who found 40 per cent reduction in PChE level in normal newborns as compared to normal adults. Low PChE activity of newborns was also observed by Abderhalden ${ }^{12}$ and Lehman. ${ }^{13}$

The inhibitory effect of dibucaine and succinylcholine on the neonatal and infant PChE corresponds to the former results in adults, ${ }^{2,3}$ in contrast to the marked resistance of neonatal and infant $\mathrm{PChE}$ to neostigmine inhibition observed in this study.

With respect to the nature of the inhibition, our results confirm those of previous investigators indicating that all three inhibitors, Sch, neostigmine, and $\ddagger$ Student t-test 

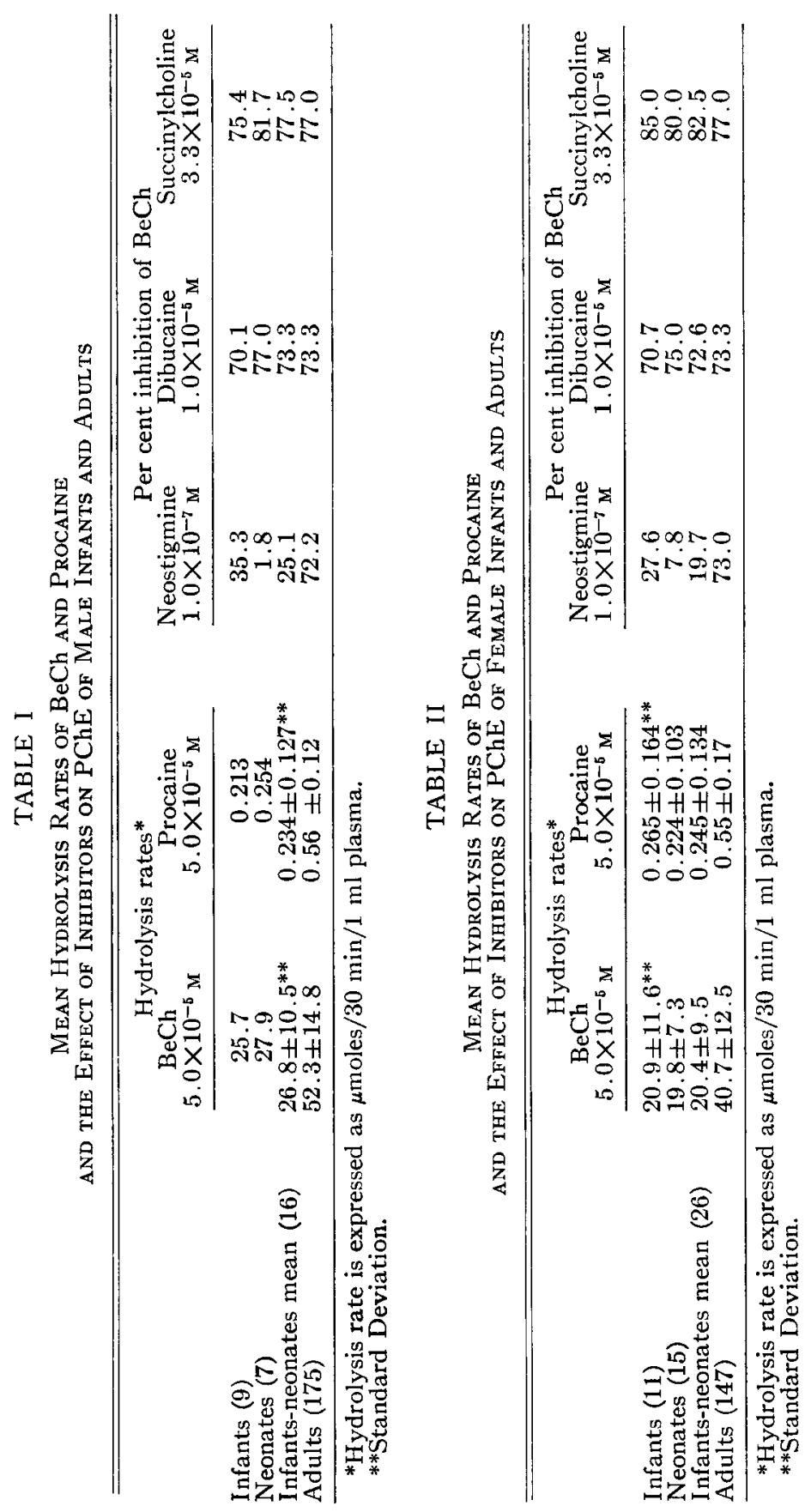


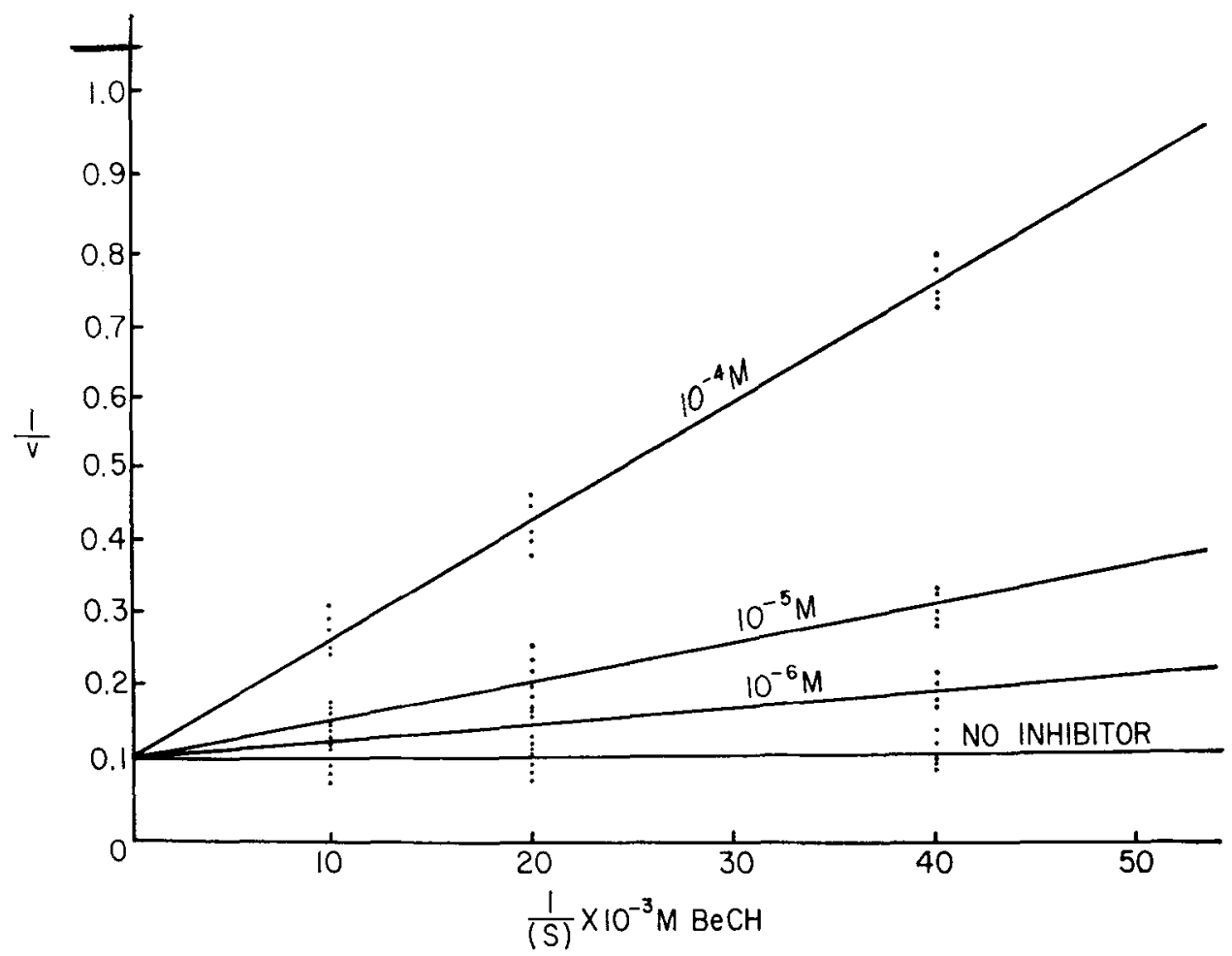

FIgure 1. Lineweaver-Burk plot of inhibition of BeCh hydrolysis by neostigmine.

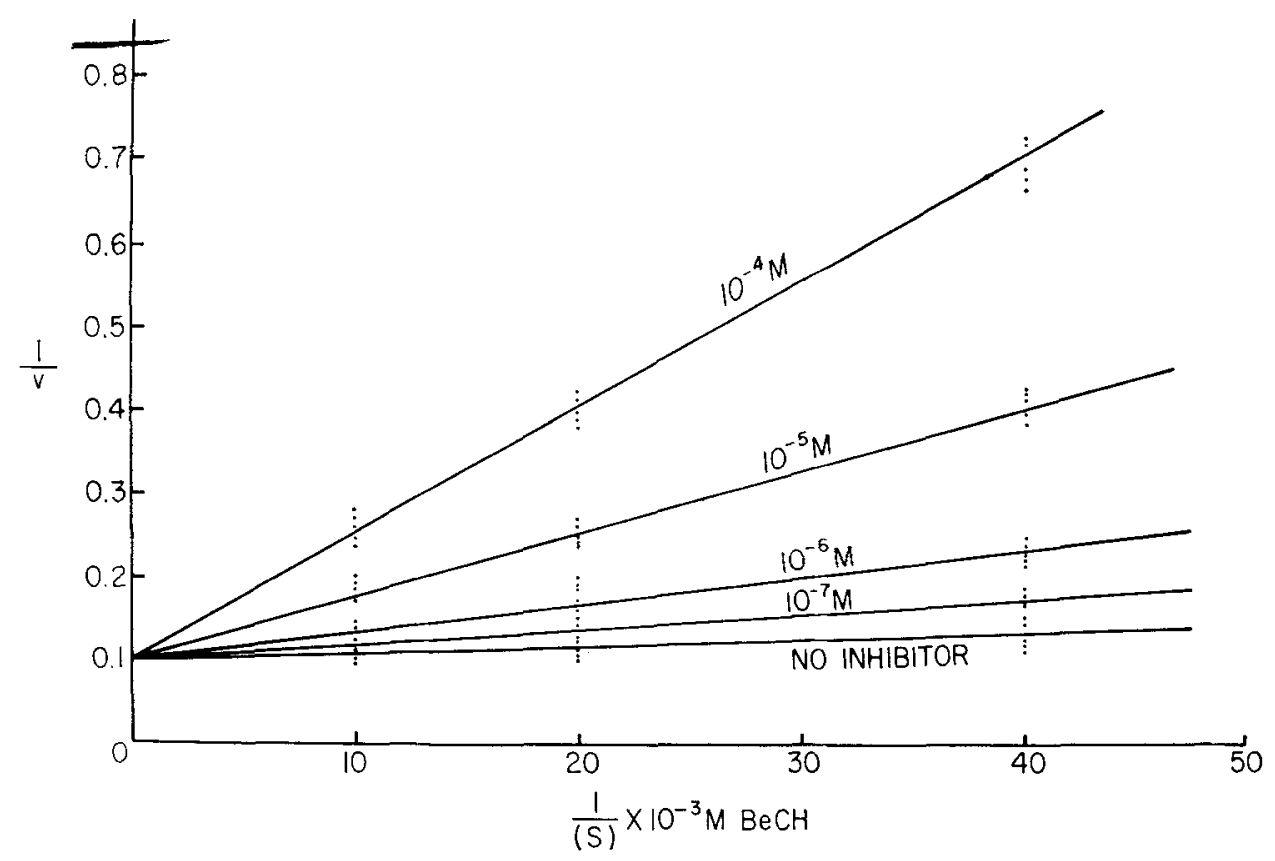

FIGURe 2. Lineweaver-Burk plot of competitive inhibition of BeCh hydrolysis by dibucaine. 


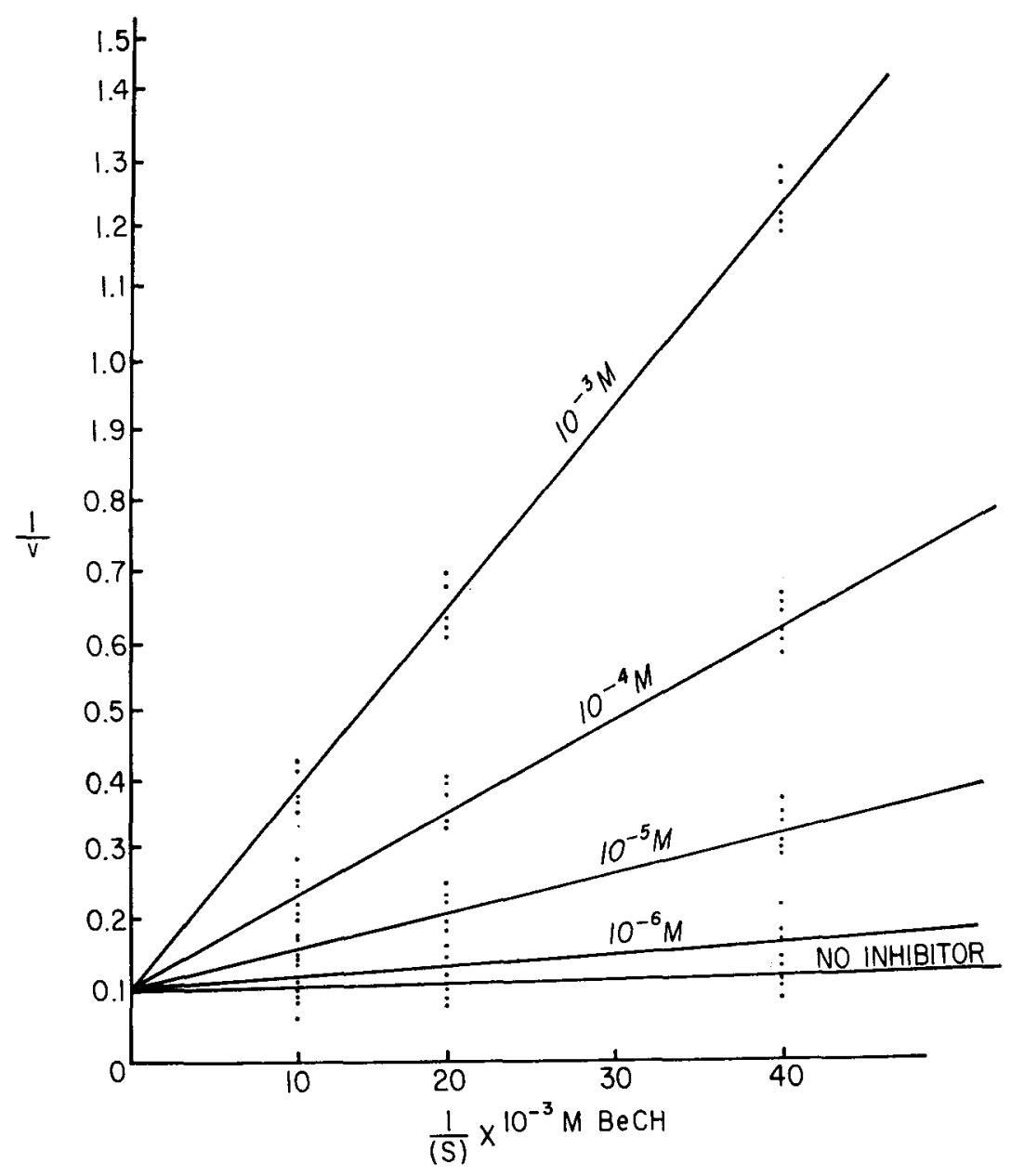

Figure 3. Lineweaver-Burk plot of competitive inhibition of BeCh hydrolysis by succinylcholine.

dibucaine caused competitive inhibition, since increasing concentrations of $\mathrm{BeCh}$ reduced the inhibitory effect. The competitive nature of the inhibition of human PChE by neostigmine, however, has recently been questioned by Foldes et al. ${ }^{14}$ who showed that the degree and type of inhibition depends not only on the concentration of neostigmine but also on the duration of preincubation with the enzyme. This point should be further clarified.

Although Telford and Keats ${ }^{15}$ reported that an inverse relationship existed between age and the Sch dose required to maintain apnea from early infancy to 10 years of age, Lim et al. ${ }^{16}$ found that infants less than 1 year old are more sensitive to this drug. The latter authors found that a dose of $0.33 \mathrm{mg} / \mathrm{Kg}$ that caused no apnea in children over a year old, did produce apnea in all infants under one year. On the other hand, even though recovery time from the neuromuscular block was shorter in infants than in children over one year, the 
muscle relaxant effect of identical intravenous doses was greater in infants than in children. This shortened recovery time may reflect a more rapid dilution of Sch in the blood of infants, since their blood volume relative to body weight is larger than that of adults or it may be due to the different sensitivity of the neuromuscular end-plates of infants to muscle relaxants as reported by ChurchillDavidson. ${ }^{17}$ The contradictory findings on the sensitivity of newborns and infants to Sch may further be reconciled by the fact that the patients studied by Telford and Keats ${ }^{15}$ had had pathologic changes which might have offset the fluid and electrolyte balance and the normal metabolic and enzyme functions.

Since there is a fixed ratio between the hydrolysis rates of $\mathrm{BeCh}$ and $\mathrm{Sch}$ in patients with normal homozygous $\mathrm{PChE}^{2}$ and since the measurement of Sch hydrolysis rates involves major inaccuracies and technical difficulties, the hydrolysis rate of PChE-Specific substrate, BeCh was accepted as an indirect measure of Sch hydrolysis rate by PChE. Consequently, it was assumed that newborns and infants hydrolyze Sch at about half the adult rate.

Although no definite conclusions can be drawn from the results of this study as to the muscle relaxant requirements or the in vivo metabolism of Sch in newborns and infants, it is definitely established that PChE activity per $\mathrm{ml}$ plasma of neonates and infants is approximately half that of adults. Therefore, it is likely that after intravenous infusion of identical $\mathrm{mg} / \mathrm{kg} / \mathrm{min}$ doses of Sch, the blood levels of Sch will be higher in newborns and infants than in adults. This assumption is corroborated by the findings of Kvisselgaard and Moya ${ }^{18}$ that the actual blood level of Sch measured by biologic titration in adult patients was primarily dependent on two factors: (1) The rate of infusion of Sch, and (2) PChE activity. Since the development of bradycardia and cardiac arrest in infants and newborns will ultimately depend on the blood level of Sch attained in the heart, we recommend that the $\mathrm{mg} / \mathrm{kg} / \mathrm{min}$ infusion rate of Sch should be reduced twofold as compared to that required in adults for complete muscle relaxation in order to avoid cardiac arrhythmias. As an alternative, the intramuscular route of administration may be chosen. The findings of Lim et $a l .{ }^{16}$ that the intravenous apneic dose of Sch in infants, younger than one year, was approximately $0.33 \mathrm{mg} / \mathrm{Kg}$ as compared to $0.66 \mathrm{mg} / \mathrm{Kg}$ in children over one year may serve as a baseline for the calculation of the safe muscle relaxant doses of Sch for this age group.

Studies on the dose-response curves of Sch with the aid of electromyography, $\mathrm{PChE}$, and actual Sch blood level determinations are currently in progress with a view toward the objective assessment of Sch sensitivity in newborns and infants.

\section{SUMMARY}

In a group of 42 healthy newborns and infants to the age of 6 months, the hydrolysis rates of benzoylcholine and procaine by the plasma cholinesterase were found to be about half the rates observed in 322 healthy adults. In contrast to adults, a marked resistance of infant plasma cholinesterase to neostigmine inhibition was found. The low plasma cholinesterase activity of newborns and infants to 6 months of age should be taken into account in the calculation 
of safe doses of succinylcholine in order to prevent cardiac arrest and/or prolonged apnea.

\section{ACKNOWLEDGEMENTS}

James W. Smudski, D.D.s., PH.D., Associate Professor and Head of the Department of Pharmacology, School of Dentistry, University of Pittsburgh, was one of the advisors for John R. Downs, D.D.s., during this investigation besides the senior author.

Procaine hydrochloride and succinylcholine chloride were supplied through the courtesy of Mr. Ira B. Cushing, Abbott Laboratories, North Chicago, Illinois; dibucaine hydrochloride by William E. Wagner, Jr., M.D., Ciba Pharmaceuticals Company, Summit, New Jersey; and neostigmine bromide and benzoylcholine chloride by Leo A. Pirk, M.D., PH.D., Hoffman-LaRoche, Inc, Nutley, New Jersey.

\section{RÉSUMÉ}

Nous avons étudié l'activité cholinestérasique du plasma chez quarante-deux nouveaux nés et des enfants de six mois. Les taux d'hydrolyse du chlorure de benzoylcholine et du chlorhydrate de procaine des nouveaux nés et des enfants ont été de 50 pour cent des taux des 322 adultes normaux, mâles et femelles. Par contraste avec les adultes normaux, une résistance de cholinestérase du plasma à linhibition par néostigmine a été observée. Il faut tenir compte de l'activité cholinestérasique réduite des nouveaux-nés et des enfants, quand on calcule les doses de chlorure de succinylcholine qui, en toute sécurité, vont prévenir l'apnée et/ou l'arrêt cardiaque.

\section{REFERENCES}

1. Tsuji, F. F.; Foldes, F. F.; \& Rhones, D. H., Jr. The Hydrolysis of Succinlycholine Chloride in Human Plasma. Arch. Int. Pharmacodyn. 104: 146 (1955).

2. Foldes, F. F.; Foldes, V.M.; Smith, J. C.; \& Zsigmond, E. K. The Relation between Plasma Cholinesterase and Prolonged Apnea Caused by Succinylcholine. Anesthesiology. 24: 208 (1963).

3. Kalow, W. \& Genest, K. A Method for the Detection of Atypical Forms of Human Serum Cholinesterase. Determination of Dibucaine Numbers. Canad. J. Biochem. 35: 339 (1957).

4. Shanor, S. P.; van Hees, G. R.; BaArt, N.; Erdös, E. G.; \& Foldes, F. F. The Influence of Age and Sex on Human Plasma and Red Cell Cholinesterase. Amer. J. Med. Sci. 242: 357 (1961).

5. Vonhaus, J. L. \& Kark, R. M. Serum Cholinesterase in Health and Disease. Amer. J. Med. 14: 707 (1953).

6. Leigh, M. D.; McCoy, D. M.; Belton, M. K.; \& Lewis, G. B., JR. Bradycardia following Intravenous Administration of Succinylcholine Chloride to Infants and Children. Anesthesiology. 18: 698 (1957).

7. Schonnstadt, D. A. \& Witcher, C. E. Observation on the Mechanism of Succinylcholine Induced Cardiac Arrhythmias. Anesthesiology. 24: 358 (1963).

8. Koelle, G. B. (sub-editor) Cholinesterases and Anti-Cholinesterase Agents. in "Handbuch der Experimentellen Pharmakologie", O. Eichler and A. Farah, editors, Berlin, Göttingen, Heidelberg, Springer Verlag, 1963, Vol. 15, p. 1220.

9. Kalow, W.; Genest, K.; \& Staron, N. Kinetic Studies on the Hydrolysis of Benzoylcholine by Human Serum Cholinesterase. Canad. J. Biochem. 34: 637 (1956).

10. Bleisch, V. R. \& Srwachman, H. Serum Cholinesterase Values in Childhood in Health and Disease. Pediatrics. 13: 426 (1954). 
11. McCance, R. A.; Hutchinson, A. O.; Dean, R. F. A.; \& Jones, P. E. H. The Cholinesterase Activity of the Serum of Newborn Animals, and of Colostrum. Biochemical J. 45: 493 (1949).

12. Abderhalden, R. Clinical Enzymology, D. Van Nostrand Company, Princeton, New Jersey, 1960, p. 41.

13. Lemman, H.; Cook, J.; \& Ryan, E. Pseudocholinesterase in Early Infancy. Proc. Roy. Soc. Med. 50: 147 (1957).

14. Foldes, F. F. \& SMItr, J. C. The Interaction of Human Cholinesterases with Anticholinesterase used in the Therapy of Myasthenia Gravis. Ann. N.Y. Acad. Sci. 135: 287 (1966).

15. Telford, J. \& Keats, A. S. Succinylcholine in Cardiovascular Surgery of Infants and Children. Anesthesiology. 18: 841 (1957).

16. Lim, H. S.; Davenport, H. T.; \& Robson, J. G. The Response of Infants and Children to Muscle Relaxants. Anesthesiology. 25: 161 (1964).

17. Churchill-Davidson, H. C. \& Wise, R. P. Neuromuscular Transmission in Newborn Infants. Anesthesiology. 24: 271 (1963).

18. Kvisselgaard, H. \& Moya, F. Estimation of Succinylcholine Blood Levels. Acta Anaesth. Scandinav. 5: 1 (1961). 